\title{
A FILOSOFIA E SEUS INTERCESSORES: DELEUZE E A NÃO-FILOSOFIA
}

JORGE VASCONCELLOS

\begin{abstract}
RESUMO: Pretendo relacionar o problema do pensamento com a criação artística em Gilles Deleuze, mostrando a importância de um pensamento diferencial, proposto pelo filósofo como nova imagem do pensamento, isto é, um pensamento que privilegia a idéia de diferença para instaurar novos ângulos e perspectivas do real. Essa aliança entre a criação artística e a produção filosófica propicia condições de possibilidade para formular uma leitura da obra deleuziana em que esse pensamento faz uma vertiginosa incursão nos domínios não-filosóficos na constituição de sua démarche. Investigarei, neste sentido, a noção de "intercessores", que, mesmo pouco tematizada na obra do filósofo, entendo tratar-se de idéia fundamental para a questão aqui em pauta.
\end{abstract}

Palavras-chave: Intercessores. Diferença. Pensamento. Criação artística.

\section{PhILOSOPHY AND ITS INTERCESSORS: DeLEUZE AND NON-PHILOSOPHY}

ABSTRACT: This paper intends to sketch out a relationship between the conceptions of thought of Gilles Deleuze and artistic creation, by showing the importance of a differential thought, which has been proposed by that philosopher as a new image of thought, i.e. a thought that privileges the idea of difference to establish new angles and perspectives about the real. Allying this artistic creation and philosophical production allows us to propose a reading of the work of Deleuze in which his thought makes a vertiginous inroad into non-philosophical domains, in the process of its own construction. Bearing this in mind, it will explore the notion of "intercessors", which, albeit little discussed in his work, seems to be fundamental for our theme.

Key words: Intercessors. Difference. Thought. Artistic creation.

Doutor em filosofia pela Universidade Federal do Rio de Janeiro (UFRJ) e professor da Universidade Gama Filho (UGF).E-mail: j_vasconcellos@uol.com.br 


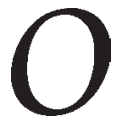

grande tema da filosofia de Gilles Deleuze é o pensamento. O exercício do pensamento e a possibilidade de novas formas de expressão do pensar percorrem toda a sua obra. Desde seus textos monográficos até as obras derradeiras, Deleuze parece propor-nos duas questões: $\mathrm{O}$ que é o pensamento? Em que medida é possível dar ao pensamento novos meios de expressão? Estes são os pontos de partida por meio dos quais porei em discussão as relações entre a filosofia e a não-filosofia em Gilles Deleuze.

Não obstante, essas questões podem ainda ser formuladas de outro modo, a saber: Como o universo extrafilosófico pode levar-nos a compreender a filosofia deleuziana em seu exercício de criação de conceitos e constituição de problemas, que vê como principal tarefa de uma nova imagem do pensamento retirar a filosofia da imobilidade em que esta se encontra colocada pela filosofia da representação? O desenvolvimento dessa questão atravessa, a meu ver, necessariamente, o problema do pensamento, de suas imagens e de seus modos de expressão.

Defendo a hipótese de que a filosofia de Gilles Deleuze é um permanente diálogo e uma conjugação entre o filosófico e o não-filosófico, e a não-filosofia desempenha um papel preponderante em seu pensamento, não apenas com relação ao estilo de sua escrita, mas fundamentalmente de modo problemático. Isso significa que a não-filosofia é utilizada como linha de fuga em face das armadilhas impostas pela representação clássica. Neste sentido, mesmo quando Deleuze privilegia em seus textos encontros com filósofos consagrados, estes, por sua vez, sempre se encontram em uma certa zona cinzenta do cânone. São sempre os que, de uma forma ou de outra, procuraram escapar das grandes armadilhas engendradas pela filosofia da representação, como, por exemplo, os estóicos, Duns Scot, Hume, Spinoza, Nietzsche e Bergson. O que importa a Deleuze não é, em última instância, privilegiar a filosofia ou mesmo a não-filosofia (a ciência e a arte), mas afirmar que tanto a arte quanto a ciência e a filosofia são, antes de mais nada, modos de pensar, expressões do pensamento. Em suma, importa tornar possível o pensamento.

Seguindo essa orientação, trabalho a partir de um problema geral e um conceito fundamental em Deleuze para equacionar teoricamente a perspectiva assumida para interpretar sua obra: trata-se do problema da imagem do pensamento e do conceito de "intercessores". Já que, para o filósofo, fazer história da filosofia é orientar-se no pensamento, precisamos para tal não só escolher os conceitos apropriados, a fim de servir de 
porta de entrada à obra de um autor, como também, e principalmente, explicitar o problema que levou tal filósofo a inventar esse conceito. Não há possibilidade de fazer filosofia, deleuzianamente falando, sem investir em um duplo campo: a constituição dos problemas e a criação dos conceitos que daí advêm, como também, para pintar o retrato do filósofo, isto é, fazer história da filosofia, faz-se necessário revelar o problema e clarificar os conceitos. Fazer história da filosofia, para Deleuze, só faz sentido se ela for problematizada: os problemas e seus conceitos. Creio que, para elaborar a perspectiva que assumo da obra deleuziana, seu retrato só pode ser pintado a partir da constituição do problema da imagem do pensamento e da gênese da criação do conceito de "intercessores".

A obra de Gilles Deleuze compreende um esforço de crítica a um tipo de pensamento designado de representação e entendido como constituição de uma filosofia da diferença. Tanto a crítica à representação quanto a construção de uma filosofia da diferença são duas faces de um mesmo movimento de pensamento; a crítica e a clínica são indissociáveis em Deleuze.

Esse problema aparece em sua obra sob a forma de uma distinção entre duas imagens do pensamento: uma imagem definida como moral, representativa, dogmática; outra, nomeada de nova imagem do pensamento ou pensamento sem imagem. É possível destacar três obras, todas da década de 1960, em que o problema é especialmente elaborado: Nietzsche e a filosofia (Deleuze, 1976, Cap. 3, \$15, "Nova imagem do pensamento"), Proust e os signos (Deleuze, 1987, Parte I, "A imagem do pensamento"), Diferença e repetição (Deleuze, 1988, Cap. 3: "A imagem do pensamento").

Em Nietzsche e a filosofia, Deleuze apresenta as três teses essenciais que constituem a imagem dogmática do pensamento. A primeira diznos que o pensador, na qualidade de pensador, quer e ama o verdadeiro - a veracidade do pensador; que o pensamento possui formalmente o verdadeiro - o inatismo da idéia, o a priori dos conceitos; pensar é o exercício natural de uma faculdade, basta pensar "verdadeiramente" para pensar com veracidade - a natureza reta do pensamento, o bom senso universalmente compartilhado. A segunda tese nos diz que somos desviados do verdadeiro por forças estranhas ao pensamento (corpo, paixões, interesses sensíveis), que nos fariam cair no erro, tomar o falso pelo verdadeiro - o erro como efeito das forças externas a se oporem ao pensamento. A terceira diz-nos que, para pensar, precisamos apenas de um método; um método que nos faça pensar bem e verdadeiramente. 
A reversão dessa imagem dogmática do pensamento é para Deleuze a tarefa da filosofia. Ainda segundo o filósofo francês, Nietzsche, em sua filosofia, reverteu essa imagem moral do pensamento e propôs uma nova imagem ao introduzir as noções de sentido e valor no exercício do pensar. Pensar não é o exercício natural de uma faculdade. $\mathrm{O}$ pensamento não pensa sozinho e por si mesmo, como também não é perturbado por forças que lhe permaneceriam exteriores. Pensar depende necessariamente das forças que se apoderam do pensamento.

Em Proust e os signos, Deleuze analisa o tema do tempo na $R e$ cherche du temps perdu e apresenta a imagem dogmática do pensamento como uma imagem racionalista da filosofia. Essa imagem racionalista, que como já dissemos pode também ser chamada de moral e representativa, é constituída de pressupostos, os quais retomam o que Deleuze já havia trabalhado em Nietzsche e a filosofia: "O filósofo pressupõe de bom grado que o espírito como espírito, o pensador como pensador, que o verdadeiro ama ou deseja o que é verdadeiro, procura naturalmente o verdadeiro. Ele antecipadamente se confere uma boa vontade de pensar” (Deleuze, 1987, p. 93). À imagem racionalista da filosofia, Proust, na leitura deleuziana, contrapõe uma nova imagem do pensamento, que terá como maior característica a relação entre as forças externas que fazem o pensamento sair de sua imobilidade, provocando encontros, intercessôes.

Os encontros têm como objeto o signo. Na nova imagem do pensamento desenvolvida em Proust e os signos, Deleuze apresenta as relações entre signos, pensamento e criação:

O que nos força a pensar é o signo. O signo é objeto de um encontro; mas é precisamente a contingência do encontro que garante a necessidade daquilo que ele faz pensar. $\mathrm{O}$ ato de pensar não decorre de uma simples possibilidade natural; ele é, ao contrário, a única criação verdadeira. A criação é a gênese do ato de pensar no próprio pensamento. (Deleuze, 1987, p. 96)

Essa gênese deve implicar alguma coisa que violente o pensamento, que o retire de seu natural estupor, de sua imobilidade, de suas abstrações. Pensar é romper com a passividade, é sofrer a ação de forças externas que o mobilizem. Pensar é, além disso, interpretar. Dito de outro modo, pensar é explicar, desenvolver, decifrar, traduzir signos. 
Em Diferença e repetição, o tema deleuziano da imagem do pensamento é elaborado com base no problema dos pressupostos em filosofia. O livro apresenta quatro postulados da imagem do pensamento, da imagem dogmática do pensamento, a qual está implícita no pensamento conceitual filosófico.

O primeiro postulado é o princípio Cogitatio natura universalis. Nesse postulado, o pensamento é apresentado como exercício natural de uma faculdade: há uma boa vontade do pensador e uma natureza reta do pensamento. $\mathrm{O}$ pensamento possui formalmente o verdadeiro e o quer materialmente.

O segundo supõe que o bom senso e o senso comum apresentam o pensamento como uma potência compartilhada por todos os homens de modo natural. É partindo do ideal do senso comum que Deleuze apresenta o terceiro postulado da imagem do pensamento: o modelo da recognição.

O modelo da recognição "se define pelo exercício concordante de todas as faculdades sobre um objeto suposto como sendo o mesmo: é o mesmo objeto que pode ser visto, tocado, lembrado, imaginado, concebido (...)" (idem, 1988, p. 221). Deleuze apresenta a imagem dogmática do pensamento fundada sobre o modelo recognitivo, o qual coloca a identidade do Eu penso na concordância de todas as faculdades e seu acordo na forma de um objeto suposto como sendo o mesmo.

$\mathrm{O}$ quarto postulado diz-nos que os elementos da representação têm, como princípio geral, o Eu penso, garantindo a unidade de todas as faculdades. Há uma quádrupla sujeição desse princípio: ao idêntico, ao semelhante, ao análogo e ao oposto - que são definidos pelos elementos gerais da representação: a identidade no conceito, a oposição na determinação do conceito, a analogia no juízo, a semelhança no objeto. Os quatro postulados da imagem dogmática ou moral do pensamento retomam em Diferença e repetição o que Deleuze já havia desenvolvido em Nietzsche e a filosofia e em Proust e os signos.

Como vimos, Deleuze alerta-nos para a existência de uma imagem do pensamento que é pré-filosófica e natural, tirada do elemento do senso comum. Essa imagem, que está em afinidade com o verdadeiro, pressupõe que nós já pensamos, isto é, que nada precisamos fazer para pensar, basta nos abrirmos aos problemas para que as soluções venham a aparecer, livre e espontaneamente; esta é a imagem moral ou dogmática do pensamento. 
Neste sentido, o pensamento conceitual filosófico tem como pressuposto implícito uma Imagem do pensamento, pré-filosófica e natural, tirada do elemento do senso comum. Segundo esta imagem, o pensamento está em afinidade com o verdadeiro, possui formalmente o verdadeiro e quer materialmente o verdadeiro. E é sobre esta imagem que cada um sabe, que se presume que cada um saiba o que significa pensar. Pouco importa, então, que a filosofia comece pelo objeto ou pelo sujeito, pelo ser ou pelo ente, enquanto o pensamento permanecer submetido a esta imagem que já prejulga tudo, tanto a distribuição do objeto e do sujeito quanto do ser e do ente. Podemos denominar esta imagem do pensamento de imagem dogmática ou ortodoxa, imagem moral. (Deleuze, 1988, p. 218-219)

Em toda a sua obra, Deleuze faz fulgurar o tema da imagem do pensamento e as possibilidades para o exercício do pensar. A tarefa da filosofia, de toda a filosofia do porvir, deve ser aquela de colocar movimento no pensamento, retirá-lo de sua imobilidade, que nada mais é que romper os pressupostos da representação e diluir seus principais elementos. Pensar é garantir ao pensamento sua possibilidade mais radical: criar conceitos. Conceitos que possam, ancorados em um plano de imanência, fazer alianças com o extrafilosófico e produzir uma violenta onda de forças que nos faça pensar. Deleuze mesmo nos diz, com relação aos conceitos e à impossível docilidade da prática do pensamento:

Na verdade, os conceitos designam tão-somente possibilidades. Falta-lhes uma garra, que seria a da necessidade absoluta, isto é, de uma violência original feita ao pensamento, de uma estranheza, de uma inimizade, a única a tirá-lo de seu estupor natural ou de sua eterna possibilidade: tanto quanto só há pensamento involuntário, suscitado, coagido no pensamento, com mais forte razão é absolutamente necessário que ele nasça, por arrombamento, do fortuito no mundo. O que é primeiro no pensamento é o arrombamento, a violência, é o inimigo, e nada supõe a filosofia; tudo parte de uma misosofia. Não contemos com o pensamento para fundar a necessidade relativa do que ele pensa; contemos, ao contrário, com a contingência de um encontro com aquilo que força a pensar, a fim de elevar e instalar a necessidade absoluta de um ato de pensar, de uma paixão de pensar. (1988, p. 230)

E Deleuze continua, apontando para as condiçôes de uma verdadeira crítica e para uma boa clínica em filosofia, o que passa, necessariamente, pelo combate à imagem dogmática ou moral e pela construção de uma nova imagem do pensamento: "As condiçôes de uma verdadeira crítica e de uma verdadeira criação são as mesmas: destrui- 
ção da imagem de um pensamento que pressupõe a si própria, gênese do ato de pensar no próprio pensamento" (1988, p. 230-231).

Além do problema da imagem do pensamento, proponho como eixo interpretativo à obra de Gilles Deleuze a idéia de intercessores. Os intercessores são quaisquer encontros que fazem com que o pensamento saia de sua imobilidade natural, de seu estupor. Sem os intercessores não há criação. Sem eles não há pensamento:

O essencial são os intercessores. A criação são os intercessores. Podem ser pessoas - para um filósofo, artistas ou cientistas; para um cientista, filósofos ou artistas - mas também coisas, plantas, até animais, como em Castañeda. Fictícios ou reais, animados ou inanimados, é preciso fabricar seus próprios intercessores. (Deleuze, 1988, p. 156)

Embora Deleuze não tenha desenvolvido em artigo ou texto a idéia de intercessores, pois a única referência explícita encontra-se no trecho desta entrevista retrocitada, considero essa noção fundamental para dar conta do método e do pensamento deleuzianos. Minha intenção é mostrar que, na verdade, os intercessores atuam no plano de imanência da filosofia deleuziana como um conceito, isto é, eles são o que propicia condiçôes de resolução do problema colocado: a imagem do pensamento. Não se trata de dizer que os intercessores são apenas alianças, encontros, apesar de eles constituírem-se enquanto tais, mas de mostrar sua importância. Isso porque, segundo Deleuze, um conceito pode ser definido a partir de cinco características.

Em primeiro lugar não há um conceito simples, isto é, todo ele possui componentes. Um conceito é formado por uma multiplicidade de elementos. Em segundo lugar, no hábitat do conceito - seu plano de imanência - é desenvolvida uma zona de vizinhança necessária com outros conceitos, estabelecendo uma relação de composição em rede: é o devir do conceito. Em terceiro lugar, cada conceito deve ser considerado o ponto de coincidência, de condensação ou de acumulação de seus próprios componentes: os conceitos organizam-se ordenadamente de modo intensivo, fugindo das facilidades da compreensão, da tentação da extensão; por isso, ele é um ato de pensamento, um incorporal no sentido estóico. Em quarto lugar, o conceito congrega em si o nível absoluto e relativo ao plano do qual se delimita e aos problemas que se supóe resolver, isto é, ele opera sobre o plano a partir das condiçôes que o problema em questão lhe impõe. Por último, o conceito não é discursivo, não é uma 
torrente de enunciados, apesar da presença de enunciações em sua forma "linguageira", isso porque ele não encadeia proposições. O que é então o conceito: a ferramenta do filosofar, o instrumento da filosofia, estando esses dados presentes em seus três elementos: no plano de imanência, que é seu hábitat, em suas personificaçôes conceituais (os personagens conceituais), que já não são mais pré-filosóficos como o plano de imanência, mas pró-filosóficos, e nos próprios conceitos. Os intercessores constituem-se, assim, em um conceito da filosofia de Gilles Deleuze, um dos mais poderosos conceitos do pensamento deleuziano. E veja que em todo momento fiz referência a "intercessores" e não a "intercessor", isso porque estamos diante de um conceito que somente se manifesta de modo plural: tratam-se sempre de intercessores a forçar o pensamento a sair de sua imobilidade.

Dito isto, ressalto que o recurso da utilização do conceito de "intercessores" não é prerrogativa apenas de quando o filósofo investiga domínios explicitamente não-filosóficos, como, por exemplo, o cinema, assim como acontece com suas pesquisas acerca da literatura, do teatro e da pintura, domínios os quais, neste sentido, também podem ser identificados como intercessores da filosofia da diferença deleuziana. Quando Deleuze se propôs a discutir com saberes não estritamente filosóficos, o que estava em jogo eram questões e problemas de orientação filosófica. Os livros sobre a arte cinematográfica liberaram conceitos de ordem filosófica para pensar o cinema, os quais, por sua vez, constituem conceitos estritamente filosóficos.

O procedimento deleuziano de reivindicar literatos, escritores, poetas, músicos e artistas em geral, como intercessores de seu pensamento, é, a meu ver, um dos mais marcantes preceitos de sua filosofia. Sendo assim, seus livros sobre as literaturas de Proust (Deleuze, 1987) e Kafka (Deleuze \& Guattari, 1975); a investigação acerca de uma lógica das sensaçôes com base na pintura de Francis Bacon (Deleuze, 1981); sua colaboração com Carmelo Bene (Deleuze \& Bene, 1979) na tentativa de pensar um teatro e uma filosofia do menos e os livros sobre o cinema apontam firmemente nessa direção. Isso sem falar na obra dedicada a Leibniz e ao barroco (Deleuze, 1986). Em todas essas intercessōes de Deleuze com domínios extrafilosóficos, o que importa fundamentalmente não são as análises que o filósofo empreendeu sobre as obras ou as artes em questão, mas os conceitos que essas mesmas obras e artes liberam à filosofia. Deleuze mesmo o diz: um pintor não precisa de um filósofo 
para pensar sobre a pintura, assim como um matemático não necessita recorrer à filosofia para problematizar questões que são próprias à matemática. Esses artistas ou cientistas pensam por si, valendo-se de questôes e problemas colocados por seus próprios domínios. O papel do filósofo é de outra natureza. $\mathrm{O}$ que o caracteriza e o diferencia de outros criadores é o fato de ele ser um inventor de conceitos. A filosofia, dentro dessa perspectiva, não é contemplação (o caminho em direção à idéia), comunicação (um jogo de intersubjetividade), ou mesmo reflexão (uma reflexão metódica sobre um objeto determinado) - filosofar é criar conceitos. Em Deleuze, essa criação de conceitos se faz a partir de apropriações de conceitos de outrem (um filósofo é um bom ladrão de idéias); de torções e conjunções com um grupo de filósofos (quase sempre filósofos que ficaram esquecidos na cartografia hegemônica da história da filosofia: estóicos, megários, Duns Scot, Spinoza ou Nietzsche); de intercessóes com saberes não-filosóficos (a literatura, a arte e a ciência; Deleuze \& Guattari, 1992). Assim, quando um filósofo como Deleuze se aproxima da literatura de um escritor como Jorge Luis Borges, isso ocorre em razão da urgência dos problemas formulados à sua filosofia. Ao deparar com um problema como as relaçóes entre tempo e verdade, problema que, por sua natureza, atravessa toda a história da filosofia, Deleuze encontra poderoso intercessor na literatura borgiana.

O conceito de "intercessores" é fundamental na démarche deleuziana. É por meio dele que podemos relacionar filosofia e arte, criação de conceitos e invenção de imagens, pois em Deleuze a questão fundamental do pensamento é a criação: pensar é inventar o caminho habitual da vida, pensar é fazer o novo, é tornar novamente o pensamento possível. Pensar é produzir idéias.

A noção de "idéia" para Deleuze, contudo não é, obviamente, a mesma no sentido platônico ou do pensamento da representação. A idéia não é dada, não é uma precondição espontânea de uma faculdade. Alguns pontos são interessantes de serem demarcados para entendermos melhor a relação entre criação e idéia em Deleuze, e é por meio dessa relação que se estabelecem os planos fundamentais do pensamento: o plano de composição da arte, o plano de referência da ciência e o plano de imanência da filosofia.

Em primeiro lugar, Deleuze diz-nos que a criação depende de uma idéia. Os criadores criam, antes de mais nada, idéias. De um cineasta a um matemático, passando por um filósofo, é de idéias que tratam 
suas criações. No entanto, as idéias da filosofia são conceitos, as da matemática funções e as da arte blocos de afectos e perceptos, blocos de sensações. Sendo que o cinema em especial inventa blocos de movimento/ duração.

Em segundo lugar, que a filosofia não é uma reflexão. Assim como os cineastas não precisam dos filósofos para refletir sobre o cinema, eles mesmos devem fazê-lo, um matemático não precisa de ninguém para pensar por ele o que é a matemática. A tarefa da filosofia tampouco é a contemplação do mundo ou das idéias, menos ainda a contemplação do mundo das idéias; além de não se prestar à informação ou à comunicação. A tarefa da filosofia é, antes de mais nada, criar conceitos. O filósofo é inventor de conceitos.

Recebido em maio de 2005 e aprovado em julho de 2005.

\section{Referências bibliográficas}

DELEUZE, G. Nietzsche a e filosofia. Trad. Ruth Joffily e Edmundo Fernandes Dias. Rio de Janeiro: Editora Rio, 1976.

DELEUZE, G. Francis Bacon: logique de la sensation. 2 vols. Paris: Editions de la Différence, 1981.

DELEUZE, G. Cinema 1. A imagem-movimento. Trad. Stella Senra. São Paulo: Brasiliense, 1985.

DELEUZE, G. Le pli: Leibniz et le baroque. Paris: Minuit, 1986.

DELEUZE, G. Proust e os signos. 8. ed. atualizada. Trad. Antonio Piquet e Roberto Machado. Rio de Janeiro: Forense, 1987.

DELEUZE, G. Diferença e repetição. Trad. Luiz Orlandi e Roberto Machado. Rio de Janeiro: Graal, 1988.

DELEUZE, G. Cinema 2. A imagem-tempo. Trad. Eloisa de Araújo Ribeiro. São Paulo: Brasiliense, 1990.

DEleuzE, G. Conversaçôes. Trad. Peter Pál Pelbart. Rio de Janeiro: Editora 34, 1992. 
DELEUZE, G.; BENE, C. Superpositions. Paris: Minuit, 1979.

DELEUZE, G.; GUATTARI, F. Kafka: pour une littérature mineure. Paris: Minuit, 1975.

DELEUZE, G.; GUATTARI, F. O que é a filosofia? Trad. Bento Prado Jr. e Alberto Alonso Muñoz. Rio de Janeiro: Editora 34, 1992. 